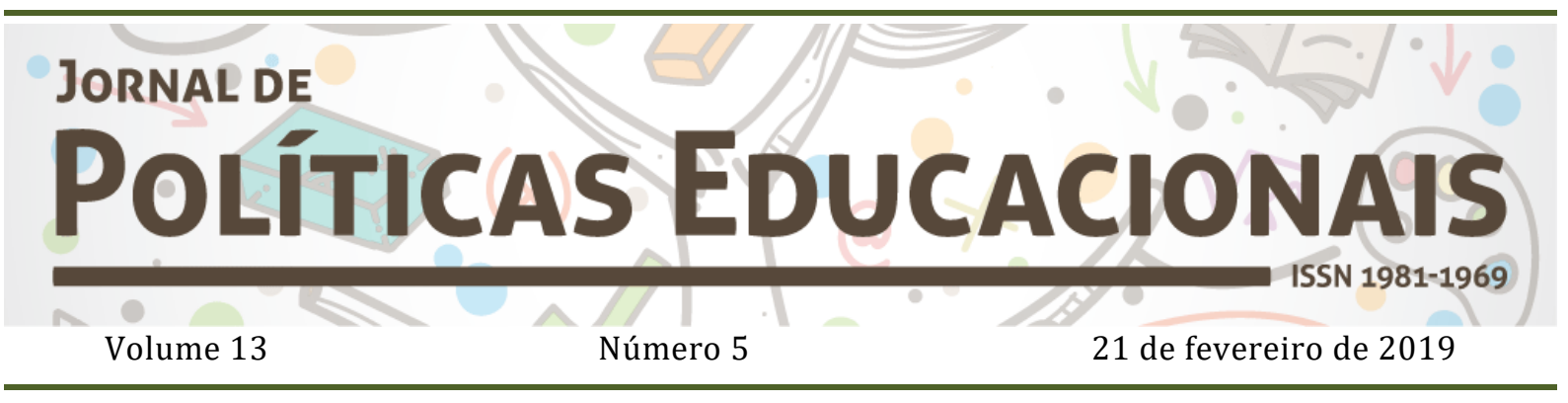

\title{
Pesquisas em políticas educacionais: questões epistemológicas e desafios à consolidação da área da Educação $(2000-2010)^{1}$
}

\section{Research on educational policies: epistemological issues and challenges to the consolidation of the education field (2000-2010)}

\section{Investigaciones en políticas educativas: cuestiones epistemológicas y desafíos a la consolidación del área de la Educación (2000-2010)}

\author{
Márcia Aparecida Jacomini² \\ Antonia Almeida Silva ${ }^{3}$
}

Citação: JACOMINI, M. A.; SILVA, A. A. Pesquisas em políticas educacionais: questões epistemológicas e desafios à consolidação da área da Educação (2000-2010). Jornal de Políticas Educacionais. V. 13, n. 5. Fevereiro de 2019.

\section{http://10.5380/jpe.v12i0.64425}

\section{Resumo}

Este estudo analisa a produção acadêmica de 20 programas de pós-graduação em educação no Brasil, notadamente teses e dissertações relacionadas ao estudo de políticas educacionais, defendidas no período 2000-2010. Procuramos apreender se e em que medida essa produção indica movimentos de superação de lacunas apontadas em alguns estudos como fatores que fragilizam a consolidação da área de Educação enquanto campo de conhecimento, nomeadamente quanto aos aspectos epistemológicos e sua articulação com os métodos de pesquisa adotados. Os trabalhos analisados anunciaram preocupações tangenciais com as questões de epistemologia, método e teoria na área educacional, mas sem, necessariamente, assumirem a constituição do campo como uma preocupação de fundo.

Palavras-chave: Política Educacional; Campo de Conhecimento; Epistemologia; Pesquisa.

\footnotetext{
Abstract

This study analyzes the academic production of 20 postgraduate programs in education in Brazil, notably theses and dissertations related to the study of educational policies, defended in the period 2000-2010. We try to understand if and to what extent this production indicates overcoming of gaps movements

${ }^{1}$ Este artigo foi produzido com base nos dados da pesquisa Questões epistemológicas e metodológicas da produção acadêmica em políticas educacionais no Brasil (2000-2010), financiada pelo CNPq. 2 Doutora em Educação pela Universidade de São Paulo (USP). Professora associada da Universidade Federal de São Paulo. E-mail: marciajacomini@uol.com.br ${ }^{3}$ Doutora em Educação pela Universidade de São Paulo. Professora titular da Universidade Estadual de Feira de Santana (UEFS). E-mail: antoniasilv@gmail.com
} 
pointed out in some studies as factors that weaken the consolidation of the education area as a field of knowledge, namely regarding the epistemological aspects and their articulation with the adopted research methods. The analyzed papers have announced tangential concerns to epistemology issues, method and theory in the educational field, but without necessarily having the constitution of the field as a fundamental concern.

Keywords: Educational Policy; Field of Knowledge; Epistemology; Research.

\section{Resumen}

Este estudio analiza la producción académica de 20 programas de postgrado en educación en Brasil, notadamente tesis y disertaciones relacionadas al estudio de políticas educativas, defendidas en el período 2000-2010. Buscamos compreender si, y en qué proporciones, esta producción indica movimientos de superacción de lacunas apuntadas en otros estúdios como factores que fragilizan la consolidación de la área de educación como campo de conocimiento, especialmente a cerca de los aspectos epistemológicos y su articulación con los métodos de investigación adoptados. Los trabajos analizados anunciaron preocupaciones tangenciales con las cuestiones de epistemología, método y teoría en el área educativa, pero sin, necesariamente, asumir la constitución del campo como una preocupación de fondo.

Palabras clave: Política Educativa; Campo de Conocimiento; Epistemología; Investigación.

\section{Introdução}

Este trabalho problematiza a produção acadêmica relacionada às políticas educacionais, tomando como corpus teses e dissertações defendidas em 20 programas brasileiros de pós-graduação em Educação, entre 2000 e 2010. Optamos pelo estudo de teses e dissertações por considerá-las parte e expressão dos movimentos de consolidação da pesquisa na universidade, haja vista o protagonismo assumido pelos programas de pós-graduação desde a década de 1980.

Em face da impossibilidade de abarcar toda produção do período no conjunto das instituições, adotou-se o critério dos programas de pós-graduação com nota igual ou superior a cinco, na avaliação da Coordenação de Aperfeiçoamento de Pessoal de Nível Superior (Capes), na trienal encerrada no ano de 2010.

Por esse critério, foram selecionadas as produções dos 20 programas com essa classificação, de 20 instituições, a saber: Pontifícia Universidade Católica de São Paulo (PUC-SP), Pontifícia Universidade Católica do Rio de Janeiro (PUC-RJ), Pontifícia Universidade Católica do Rio Grande do Sul (PUC-RS), Universidade de São Paulo (USP), Universidade do Vale do Rio dos Sinos (Unisinos), Universidade Estadual de Campinas (Unicamp), Universidade Estadual do Rio de Janeiro (Uerj), Universidade Estadual Paulista "Júlio de Mesquita Filho" campus Marília (Unesp-Marília), Universidade Federal de Goiás (UFG), Universidade Federal de Minas Gerais (UFMG), Universidade Federal de Pelotas (Ufpel), Universidade Federal de São Carlos (Ufscar), Universidade Federal de Uberlândia (UFU), Universidade Federal do Espírito Santo (Ufes), Universidade Federal do Paraná (UFPR), Universidade Federal do Rio de Janeiro (UFRJ), Universidade Federal 
do Rio Grande do Norte (UFRN), Universidade Federal do Rio Grande do Sul (UFRGS), Universidade Federal Fluminense (UFF), Universidade Metodista de Piracicaba (Unimep). Pelo critério da nota foram selecionados dois programas na Universidade Federal de São Carlos: Educação Especial e Educação. Ao término da coleta de dados, verificou-se que, dos 21 programas selecionados, em 20 programas ocorreram produções correlacionadas com políticas educacionais, ficando de fora desse universo o programa da PUC-SP, em que não foram encontradas teses e dissertações com esse enfoque. Por meio deste estudo, procuramos caracterizar as produções quanto às orientações epistemológicas, ao referencial teórico e aos métodos de pesquisa adotados.

Foram catalogadas, ao todo, 1.283 teses e dissertações analisadas, numa primeira fase da pesquisa, com base nos resumos. As produções foram classificadas em nove eixos: (1) Planejamento e Gestão; (2) Avaliação; (3) Qualidade; (4) Estado e Reformas Educacionais; (5) Políticas de formação de professor e carreira docente; (6) Financiamento; (7) Abordagens teórico-metodológicas; (8) Análise de Programas e Projetos (9) Políticas Inclusivas. Esse primeiro estudo proporcionou um panorama das características gerais das produções. Na segunda fase da pesquisa voltamo-nos mais especificamente à análise das produções classificadas no eixo sete "Abordagens teóricometodológicas", não mais com base nos resumos, mas no estudo integral das produções ${ }^{4}$.

Nesse eixo foram classificados 22 trabalhos que estudaram a produção acadêmica em políticas educacionais e em educação, sob diversas perspectivas, com atenção especial àqueles que se debruçaram sobre as questões de epistemologia, de método e de teoria na área educacional.

Este artigo foi organizado em três tópicos, além desta introdução. No primeiro, dialogamos com a literatura que trata das questões de ordem epistemológica, teórica e de método nas pesquisas em educação, especialmente na particularidade das pesquisas em políticas educacionais, procurando evidenciar os desafios anunciados para a consolidação do campo, desde a década de 1980. No segundo, caracterizamos e analisamos os dados empíricos, especialmente no que concerne aos aspectos epistemológicos e de método que se manifestam nas produções selecionadas. Nas

\footnotetext{
${ }^{4}$ Uma explicitação sobre os procedimentos da pesquisa consta no livro Pesquisa em políticas educacionais: características e tendências, organizado por Antonia Almeida Silva e Márcia Aparecida Jacomini (2016).
} 
considerações finais, apresentamos uma síntese, confrontando os achados da pesquisa com alguns referentes encontrados na literatura.

\section{A pesquisa em educação e em políticas educacionais: desafios à produção de conhecimento desde a pós-graduação}

Na literatura que consultamos, os termos "área de saber" e "campo de saber ou de conhecimento" têm sido muitas vezes empregados de forma equivalente, para se referir às fronteiras disciplinares. Sem negarmos as possibilidades interpretativas que atravessam os termos, com inspiração em Bourdieu (2004), situamos o campo como um espaço de luta que produz formas particulares de ilusio em torno dos interesses científicos em jogo. Essa noção abrange as dimensões subjetivas e objetivas que modelam os meios recursais da pesquisa (de ordem epistemológica ou instrumental), com vista ao reconhecimento entre os pares. Tal reconhecimento, baseado em "contratos tácitos", muitas vezes, acaba por constituir-se no elemento organizador da produção e nem sempre corresponde à reflexão sobre os sentidos do conhecimento produzido. Nas palavras do próprio Bourdieu,

[...] o que faz a especificidade do campo científico é aquilo sobre o que os concorrentes estão de acordo acerca dos princípios de verificação da conformidade ao "real", acerca dos métodos comuns de validação de testes e de hipóteses, logo sobre o contrato tácito, inseparavelmente político e cognitivo, que funda e rege o trabalho de objetivação (BOURDIEU, 2004, p. 33, itálicos do autor).

Em diálogo com essa compreensão, referimo-nos a campo para designar as posições e relações dos pesquisadores com a produção do conhecimento em educação, procurando discriminar os interesses científicos que vêm mobilizando os estudos e as estratégias para o seu reconhecimento, a indicação de suas orientações epistemológicas, assim como dos métodos de pesquisa.

Entre alguns pesquisadores da área, os balanços sobre a pesquisa e a produção acadêmica em educação não são recentes e são atravessados por preocupações acerca dos seus fundamentos, como demonstram os estudos de Brandão (1986), Georgen (1986), Kuenzer (1986), Damasceno (1986), Gamboa (1987); Warde (1990), André (2001), Nosella (2010), Gatti (2012), os quais indicam lacunas de ordens diversas que afetam o desenvolvimento e reconhecimento desse campo de saber. É comum, no entanto, a observância de estágios ou fases da pesquisa, especialmente a partir de 
meados da década de 1950, com poucas divergências entre as interpretações nos estudos de Gouveia (1971) e Cunha (1979).

No seio desse debate, Goergen (1986), no artigo "A pesquisa educacional no Brasil: dificuldades, avanços e perspectivas", publicado na Revista Em Aberto, em número dedicado à pesquisa em educação, toma como ponto de partida para o anúncio de suas preocupações os silêncios em torno do "estatuto de cientificidade" entre os pesquisadores brasileiros, inclusive os vinculados à pós-graduação. Combinado a isso questiona o distanciamento entre pesquisas teóricas e empíricas, como se uma negasse a cientificidade da outra. Na interpretação do autor,

Este distanciamento entre os estudos teóricos e as pesquisas empíricas é o quadro que ainda caracteriza os programas de pós-graduação, nos quais se agrupam pesquisas empíricas, muitas vezes estudos de caso que abordam recortes mínimos da realidade com alcance explicativo muito limitado e estudos teóricos que manejam conceitos totalmente distanciados da realidade, cujo potencial de aproveitamento também é muito reduzido (GOERGEN, 1986, p. 9).

Nesse contexto, o autor critica o que se convencionou chamar de teoricismo e empiricismo, assim como o modismo metodológico que tem conduzido os pesquisadores a utilizarem determinados métodos mais por profissão de fé do que pela adequação para analisar o objeto da pesquisa (GOERGEN, 1986).

Nesse mesmo número da revista Em Aberto encontram-se os textos de Kuenzer (1986), Damasceno (1986) e Brandão (1986), que exploram outras nuanças do debate.

Kuenzer (1986) assinala a descontinuidade, a heterogeneidade da formação dos pesquisadores e a dispersão, como desafios para a área. Entre as dificuldades para superar esse cenário, apresenta aspectos que perduram ainda hoje.

Por um lado, os professores das universidades têm os seus encargos aumentados, havendo diminuição progressiva da dedicação à pesquisa; por outro lado, as agências financeiras não têm assegurado as condições necessárias à consolidação de grupos de pesquisadores através da criação de mecanismos de apoio que garantam a continuidade das pesquisas que têm sido realizadas (KUENZER, 1986, p. 19).

No que tange à heterogeneidade da formação, chama atenção para o fato de $46 \%$ dos doutores e mestres serem qualificados no exterior, o que teria implicado na apropriação de paradigmas teóricos e metodológicos alheios aos determinantes sociais, econômicos e culturais do Brasil, o que, guardadas as devidas proporções, "justifica o empirismo como método" (p. 20) e uma produção eminentemente descritiva, entre 
muitos pesquisadores. Essa crítica da autora não a faz ser menos atenta aos problemas acarretados pelas contradições vivenciadas por pesquisadores que passaram a explorar as relações entre as questões econômicas e sociais, mas presos à dicotomia entre teoria e prática. Em seu entender, pensar a qualidade das pesquisas exige avançar além da imediaticidade do real, captar a totalidade do desenvolvimento social, compreendendo-o como processo histórico. O sentido social da investigação e as condições para a sua efetivação são dimensões centrais para se alcançar a qualidade. Esta, por sua vez, implica na capacidade de compreender, analisar e indicar caminhos que corroboram para a transformação da realidade educacional, sem que se confunda esses movimentos com a busca pela funcionalidade imediata da pesquisa.

Em direção similar, Azanha (1992, p. 20) alerta que é necessário afastar a "exacerbada preocupação da grande parte da pesquisa educacional com a obtenção de resultados práticos", quando é preciso considerar que o tempo da investigação é diferente daquele das demandas que exigem decisões rápidas. Certamente, a ponderação sobre a relação da pesquisa e sua aplicabilidade não é uma questão menor. Todavia colocá-la em debate não desobriga os pesquisadores a considerarem a realidade educacional na produção de suas investigações, mas sinaliza para as limitações das abordagens que se fixam na funcionalidade dos resultados e suas implicações, sobretudo ao reduzir as dimensões contraditórias da acumulação de conhecimento, reconstrução e inventividade a gestos pragmáticos, especialmente dentro da lógica mercadológica que impera na contemporaneidade.

Damasceno (1986) agrega a essas incursões a importância da perspectiva epistemológica do pesquisador e o papel do método como integrador do fenômeno estudado no contexto social. Dado que a ciência é um produto cultural e está permeada pela visão de mundo de quem a produz, a autora ressalta a importância de se cuidar dessas questões na produção de conhecimento, numa perspectiva científica que rompa com o paradigma positivista que reduz o pesquisador a um "observador imparcial".

No mesmo dossiê, Brandão (1986, p. 26) indica suas preocupações com a pseudoexpansão da pós-graduação. A autora mostra-se particularmente preocupada com a preparação dos mestrandos para os requisitos mínimos de metodologia e efetiva imersão na pesquisa e as tendências credencialistas que envolvem as instituições. "A trajetória da pós-graduação em educação (e certamente a de outras áreas) deve ser 
entendida dentro desta rota credencialista, que impôs uma política educacional dependente e de interesses espúrios à área" (BRANDÃO, 1986, p. 26).

Desde então está posta a lógica credencialista, alheia à natureza e especificidade da educação e às condições para o seu desenvolvimento como um campo de estudo. A subordinação a essa lógica não só tem acirrado as relações hierárquicas entre as áreas de conhecimento, mas incidido sobre os tempos e os processos de formação dos pesquisadores e a sua posterior atuação profissional, sobretudo por meio da vinculação da produção de conhecimento aos interesses do mercado. Nesse cenário, debater a formação de pesquisadores, associada ao domínio dos paradigmas do campo, apresentase como face importante das disputas por espaço e afirmação dos atores em cena. Isso, para além das fronteiras nacionais, é sobejamente percebido por intelectuais como Bourdieu (2004) e Kuhn (1998). Para este último, o estudo dos paradigmas

[...] é o que prepara basicamente o estudante para ser membro da comunidade científica determinada na qual atuará mais tarde. Uma vez que ali o estudante reúne-se a homens que aprenderam as bases de seu campo de estudo a partir dos mesmos modelos concretos, sua prática subsequente raramente irá provocar desacordo declarado sobre pontos fundamentais (KUHN, 2005, p. 30).

Nessa inferência, o "comprometimento dos pesquisadores com as regras e padrões da prática científica" é estruturante para a "gênese e a continuação de uma tradição de pesquisa determinada" (idem, p. 31), indicando as vinculações entre a formação dos pós-graduandos, futuros pesquisadores e responsáveis pela memória da produção existente e sua consolidação, em conformidade com os princípios de cientificidade preconizados no campo.

Diferente disso, porém, o que vimos com Brandão (1986) e demais autores mencionados, são dissenções acerca dos processos empreendidos, especialmente aqueles em curso (subsunção ao credencialismo) e suas implicações sobre a efetiva imersão na pesquisa. Sem entrar no mérito de possíveis nostalgias sobre as memórias do passado, conforme problematizam Macedo e Sousa (2010), é certo que esses balanços sobre a pesquisa em educação (e seus produtos na forma de teses e dissertações) não remetem apenas ao passado.

Mais recentemente, estudos como os de André (2001), Nosella (2010) e Gatti (2012) seguiram sinalizando para os desafios da pesquisa em educação, sem deixar de lado o lugar da pós-graduação nesse processo. Entre as preocupações de Nosella (2010) 
emergem a fragmentação epistemológica e temática. Destarte, assinala como desafios: "revigorar a teoria, melhorar as narrativas, rever o processo de avaliação, institucionalizar a pesquisa nas novas universidades" (NOSELLA, 2010, p. 180).

São notórias, nas incursões dos diferentes autores, preocupações com a integração empírico-teórica das pesquisas e o seu engajamento político-social. Destacam-se também seus esforços para acentuar as relações entre os padrões de pesquisa dominantes em cada "estágio" e as dinâmicas socioeconômicas hegemônicas dos últimos 60 anos. Todos, porém, exploram mais elementos sensitivos, do que empíricos propriamente, o que, porém, não invalida as inferências, mas antes revela a percepção de profissionais experientes e com grande influência sobre as ideias que circulam no campo.

Numa dimensão mais operacional sobre a lógica da pesquisa científica, Gamboa acentua a dialética entre pergunta e resposta e os movimentos que atravessam essa relação, distinguindo quatro níveis que se implicam: o nível técnico, que diz respeito à forma de coleta, sistematização e tratamento dos dados; o nível metodológico, que refere-se ao processo da pesquisa, à forma de aproximação do objeto, à delimitação do todo e à relação com as partes; o nível teórico, em que se encontram as escolhas acerca do núcleo conceitual básico, fenômenos privilegiados, autores selecionados, mudanças propostas; e, por último, o nível epistemológico, que diz respeito aos critérios de construção do objeto científico e abrange três dimensões indissociáveis: a) "concepção de casualidade, de validação da prova científica e de ciência (critérios de cientificidade)"; b) os pressupostos gnosiológicos, "maneiras de abstrair, generalizar, conceituar, classificar e formalizar, ou maneiras de relacionar o sujeito e o objeto; c) os pressupostos ontológicos, "categorias abrangentes e complexas, concepção de Homem, Educação e Sociedade, concepções de realidade (concepção de espaço, tempo e movimento)", que se referem à cosmovisão (GAMBOA, 2015, p. 79).

No universo da educação, mas com enfoque mais específico, os pesquisadores de políticas educacionais também têm circulado preocupações semelhantes, notadamente em relação à enunciação dos parâmetros ou referenciais epistemológicos e de método que orientam as pesquisas, como denotam Masson (2007 e 2012); Tello; Mainardes (2012); Tello (2013).

Tello (2013) apresenta três componentes para os estudos sobre as epistemologias das políticas educacionais: a) a perspectiva epistemológica, b) o 
posicionamento epistemológico e c) o enfoque epistemetodológico. 0 primeiro refere-se à cosmovisão ou teoria geral que o investigador assume para guiar o seu percurso. Já o posicionamento epistemológico abrange as correntes teóricas próprias do campo de conhecimento a que a pesquisa se vincula, as quais são derivadas da perspectiva epistemológica e encerram a posição ideológica e política do pesquisador. 0 enfoque epistemetodológico, por sua vez, refere-se ao modo como o pesquisador concebe a metodologia, não no sentido estrito de mero instrumento de coleta e análise de dados, mas como se estrutura o pensamento. 0 termo "epistemetodológico" decorre da compreensão de que há articulação entre a perspectiva epistemológica e o método do pesquisador.

Reconhecendo a importância desses estudos para uma aproximação com a memória e os modos de interpretação que vêm circulando sobre a produção acadêmica e a pesquisa, tanto em educação, quanto em políticas educacionais, de modo mais específico, voltamo-nos a seguir para o exercício de analisar as 22 produções, procurando ampliar as percepções em torno das lacunas acentuadas pelos autores e os dados empíricos aqui cotejados.

Assim, compreendemos que as referências epistemológicas nas pesquisas em educação, especialmente em políticas educacionais, abrangem as bases sobre as quais o autor define seu objeto, organiza a pesquisa e a realiza, tendo em vista os valores que informam sua visão de mundo, de natureza humana, de conhecimento, de educação, de políticas educacionais. Algo semelhante ao que Losada e Casas (2010) estabeleceram em torno da compressão de macromoldes e suas relações com valores primordiais na pesquisa.

Son grandes escuelas de pensamento, entendendo por tales, em cada caso, um conjunto de valores primordiales, princípios y ejemplos sobre como avanzar em uma ciencia específica, compartidos por um conjunto de profissionales de la disciplina correspondiente, el cual guia su atividade investigativa (LOSADA; CASAS, 2010, p. 48).

Para efeito da análise da produção acadêmica a ser empreendida no próximo item, em diálogo com esses autores, porém sem adotar completamente nenhuma das propostas de análise apresentadas, foram indicadas as referências epistemológicas mais amplas e o referencial teórico mais específico, pelo critério de autoidentificação dos autores, embora estes nem sempre tenham feito uso dessa nomenclatura. 0 referencial teórico não diz respeito ao conjunto de autores citados nas teses e dissertações, mas 
àqueles eleitos para dar sustentação às análises e que, supostamente, ajudam o pesquisador a fazer avançar o conhecimento.

A explicitação desses elementos nos trabalhos de mestrado e doutorado indica a consciência do pesquisador acerca do processo de pesquisa e dos pressupostos que o norteiam, contudo o mais importante é que o trabalho tenha articulação coerente entre os elementos ordenadores assumidos pelos pesquisadores.

\section{As características das pesquisas e os desafios para o campo: epistemologia, referencial teórico e método}

As 22 teses e dissertações que são objeto de análise neste tópico foram classificadas no eixo "Abordagens teóricas e epistemológicas" após a leitura inicial do resumo. Para o desenvolvimento das análises, além da leitura completa dos trabalhos, foi elaborada uma ficha analítica, com a finalidade de compor um quadro informativo com dados tais como: palavras-chave, linha de pesquisa, caracterização dos resumos, descrição do conteúdo de cada capítulo, objetivo, questão de pesquisa, informações explícitas do método, perspectiva epistemológica, referencial teórico, principais conclusões, entre outros.

Ao todo foram reunidas 12 teses e 10 dissertações, das quais 18 foram defendidas no período de 2006 a 2010 e quatro entre os anos de 2002 a 2004, com a seguinte distribuição por ano: 2002 (1), 2003 (1), 2004 (2), 2006 (3), 2007 (6), 2008 (2), 2009 (4), 2010 (3). Observa-se que, mesmo modesto, houve aumento da produção sobre a temática na segunda metade da década de 2000. Contudo, considerando que no universo de 1.283 trabalhos catalogados somente 22 trabalhos emergiram na coleta com as palavras-chave "abordagens teórico-metodológicas", é notório que essa temática não foi uma preocupação muito presente entre os trabalhos de mestrado e doutorado.

As teses e dissertações analisadas foram produzidas em oito instituições de três unidades da federação, sendo 12 no Rio de Janeiro (7 na UERJ, 4 na UFRJ, 1 na PUC-RIO), nove em São Paulo (5 na Unesp-Marília, 1 na Unimep, 1 na Feusp, 2 Ufscar) e uma no Rio Grande do Sul (UFPel), conforme Quadro 1. Tal distribuição revela a concentração de trabalhos em universidades do Rio de Janeiro (estadual e federal) e São Paulo (estadual).

A leitura integral dessas produções indicou a necessidade de classificação interna em três grupos temáticos, considerando as suas especificidades. Um grupo com oito trabalhos que pautaram a produção científica e acadêmica da educação. Outro com 
quatro trabalhos que tratam de temáticas diversas e não debatem a questão da produção do conhecimento propriamente. Por último, um grupo com 10 trabalhos que focalizaram políticas educacionais específicas e desenvolveram pesquisas do tipo estudos de revisão (estado da arte, revisão bibliográfica, revisão sistemática etc.), conforme Quadro 1.

Quadro 1 - Classificação dos trabalhos por agrupamentos temáticos

\begin{tabular}{|c|c|c|c|c|}
\hline $\begin{array}{l}\text { Agrupamentos } \\
\text { temáticos }\end{array}$ & Título & Instituição & Ano & Tipo \\
\hline \multirow{8}{*}{$\begin{array}{l}\text { Estudos sobre } \\
\text { a produção } \\
\text { científica e } \\
\text { acadêmica da } \\
\text { Educação }\end{array}$} & $\begin{array}{l}\text { A pesquisa em educação no Brasil no contexto } \\
\text { do pensamento epistemológico de Gaston } \\
\text { Bachelard }\end{array}$ & UERJ & 2006 & $\mathrm{~T}$ \\
\hline & $\begin{array}{l}\text { A questão da teoria e o pragmatismo dos } \\
\text { métodos e técnicas em educação }\end{array}$ & UERJ & 2002 & D \\
\hline & $\begin{array}{l}\text { O papel da escola superior de guerra na projeção } \\
\text { do campo militar sobre o campo educacional }\end{array}$ & UFRJ & 2010 & $\mathrm{~T}$ \\
\hline & $\begin{array}{l}\text { Educação e Neopragmatismo: a questão da } \\
\text { verdade em Richard Rorty e suas repercussões } \\
\text { no campo da educação }\end{array}$ & UERJ & 2009 & $\mathrm{~T}$ \\
\hline & $\begin{array}{l}\text { O processo da produção do conhecimento em } \\
\text { educação: a questão da imaginação }\end{array}$ & UERJ & 2007 & $\mathrm{D}$ \\
\hline & $\begin{array}{l}\text { A problematização do 'problema': uma leitura } \\
\text { dos manuais de iniciação ao ofício de } \\
\text { pesquisador em educação }\end{array}$ & UERJ & 2007 & $\mathrm{D}$ \\
\hline & $\begin{array}{l}\text { Pedagogia e Educação: a construção de um } \\
\text { campo científico }\end{array}$ & UFRJ & 2007 & $\mathrm{~T}$ \\
\hline & $\begin{array}{l}\text { A presença da pesquisa no processo de } \\
\text { implantação da pós-graduação em educação no } \\
\text { Brasil (1960-1980) }\end{array}$ & UERJ & 2007 & $\mathrm{~T}$ \\
\hline \multirow{4}{*}{$\begin{array}{l}\text { Temáticas } \\
\text { diversas }\end{array}$} & $\begin{array}{l}\text { A escola pública hoje: desafios e possibilidades } \\
\text { de uma discussão/reflexão ancorada nas } \\
\text { perspectivas teórico-metodológicas }\end{array}$ & UFPel & 2010 & $\mathrm{D}$ \\
\hline & $\begin{array}{l}\text { As publicações sobre o projeto político- } \\
\text { pedagógico - } 1996 \text { a 2006: contribuições para a } \\
\text { organização da educação brasileira }\end{array}$ & $\begin{array}{l}\text { Unesp- } \\
\text { Marília }\end{array}$ & 2009 & D \\
\hline & $\begin{array}{l}\text { Gestão em questão: da (des)construção à } \\
\text { (re)construção }\end{array}$ & UFRJ & 2007 & $\mathrm{~T}$ \\
\hline & $\begin{array}{l}\text { Notas filosóficas sobre desejo e prazer, política e } \\
\text { educação }\end{array}$ & UERJ & 2006 & D \\
\hline \multirow{3}{*}{$\begin{array}{l}\text { Estudos de } \\
\text { revisão }\end{array}$} & $\begin{array}{l}\text { A relação Estado e Educação na produção } \\
\text { acadêmica brasileira }\end{array}$ & USP & 2003 & $\mathrm{~T}$ \\
\hline & $\begin{array}{l}\text { NUPES: Protagonista de uma história recente da } \\
\text { política para Educação Superior Brasileira? } \\
(1989-2005)\end{array}$ & UFSCar & 2008 & $\mathrm{D}$ \\
\hline & $\begin{array}{l}\text { A pesquisa educacional sobre a escola pública de } \\
\text { ensino fundamental, nos projetos e relatórios de } \\
\text { pesquisa elaborados por docentes das } \\
\text { universidades brasileiras }\end{array}$ & UFRJ & 2004 & $\mathrm{~T}$ \\
\hline
\end{tabular}


JACOMINI, M. A.; SILVA, A. A. Pesquisas em políticas educacionais: questões epistemológicas e desafios à consolidação da área da Educação (2000-2010).

\begin{tabular}{|l|l|c|c|c|}
\hline $\begin{array}{l}\text { A construção do conhecimento sobre a formação } \\
\text { do administrador escolar: uma análise a partir } \\
\text { das publicações nacionais }\end{array}$ & $\begin{array}{c}\text { Unesp- } \\
\text { Marília }\end{array}$ & 2010 & D \\
\hline $\begin{array}{l}\text { O regime de progressão continuada no Estado de } \\
\text { São Paulo: indicadores e perspectivas para novas } \\
\text { pesquisas }\end{array}$ & $\begin{array}{c}\text { Unimep- } \\
\text { Piracicaba }\end{array}$ & 2009 & D \\
\hline $\begin{array}{l}\text { As publicações da ANPAE e a trajetória do } \\
\text { conhecimento em educação no Brasil }\end{array}$ & $\begin{array}{l}\text { Unesp- } \\
\text { Marília }\end{array}$ & 2004 & $\mathrm{~T}$ \\
\hline $\begin{array}{l}\text { Planejamento escolar: um estudo a partir de } \\
\text { produções acadêmicas (1961-2005) }\end{array}$ & $\begin{array}{l}\text { Unesp- } \\
\text { Marília }\end{array}$ & 2007 & $\mathrm{~T}$ \\
\hline $\begin{array}{l}\text { A produção e circulação de saberes sobre o } \\
\text { financiamento da educação no Brasil (1991- }\end{array}$ & $\begin{array}{l}\text { Unesp- } \\
\text { 2005) }\end{array}$ & Marília & 2008 & $\mathrm{D}$ \\
\hline $\begin{array}{l}\text { A "educação ideológica" no Projeto de } \\
\text { Desenvolvimento Nacional do ISEB (1955-1964) }\end{array}$ & PUC-RJ & 2006 & $\mathrm{~T}$ \\
\hline $\begin{array}{l}\text { Os estudos de educação comparada } \\
\text { internacional no banco de dissertações e teses } \\
\text { da Capes no período de 1987 a 2006 }\end{array}$ & UFSCar & 2009 & $\mathrm{D}$ \\
\hline
\end{tabular}

Fonte: elaborado pelas autoras com base na leitura das 22 teses e dissertações classificadas no eixo sete.

As teses e dissertações estão vinculadas a 12 diferentes linhas de pesquisa, sendo que numa linha foram defendidos sete trabalhos, em outra quatro, em três linhas dois trabalhos cada uma, e em cinco linhas um trabalho cada. Tem-se, portanto, concentração de trabalhos em duas linhas "Conhecimento, Autonomia e Participação", da UERJ (7) e "Política Educacional, Administração de Sistemas Educativos e Unidades Escolares" da Unesp de Marília (4).

As pesquisas foram orientadas por 17 professores. Somente uma professora da UERJ orientou seis, os demais orientaram uma cada. Considerando a quantidade e o conteúdo das pesquisas orientadas pela professora da UERJ, observa-se o seu direcionamento constante para a problematização da produção de conhecimento e sua relação com a área da Educação, ora enfocando o pensamento e obra de algum intelectual influente na filosofia (Richard Rorty e Gaston Bachelard, por exemplo), ora enfocando vieses da produção de conhecimento em suas dimensões procedimentais e/ou epistemológicas.

Conforme as informações anunciadas pelos próprios autores, no Quadro 2 apresentamos uma síntese do exercício que realizamos de análise dos trabalhos. 0 quadro compreende cinco colunas, orientadas pela sequência: identificador dos trabalhos (ID), título, epistemologia, referencial teórico e método. Cabe registrar que, para efeito da classificação apresentada, admitimos na coluna "Epistemologia" os pressupostos gerais que orientaram os trabalhos, mesmo quando os autores das teses e 
dissertações não empregaram essa terminologia. 0 nível epistemológico diz respeito à teoria geral dos autores e à cosmovisão que deixaram transparecer, próximo do que estabelecem Gamboa (2015), Losada e Casas (2010) e Tello (2013).

No Quadro 2 estão situados entre as linhas de um a oito os trabalhos que se dedicaram a estudos de cunho teórico sobre a produção do conhecimento em educação (Estudos sobre a produção científica e acadêmica da Educação). Os quatro trabalhos seguintes, situados entre as linhas nove a 12 , tratam de temáticas diversas e não debatem a questão da produção do conhecimento propriamente. Como já indicado, esse reconhecimento só foi possível com a leitura integral dos trabalhos, pois, embora eles anunciassem relações com a problemática da produção de conhecimento em educação nos resumos, nem sempre foram fiéis a isso, tampouco desenvolveram estudos de revisão sobre temas específicos, como ocorreu com os 10 trabalhos seguintes, situados entre as linhas 13 e 22.

Os trabalhos identificados de 13 a 22 tiveram em comum o interesse por alguma temática da área de Educação e das políticas educacionais. Todos eles tomaram como objeto de estudo a produção acadêmica relativa a algum tema. Com exceção do trabalho 17 - que se propôs a analisar as características teórico-metodológicas dos trabalhos sobre progressão continuada no estado de São Paulo -, os demais não analisaram os trabalhos no que se refere às questões epistemológicas, teóricas e de método. 0 foco principal desses trabalhos recaiu sobre a contribuição deles sobre do tema pesquisado.

QUADRO 2 - Características de teses e dissertações quanto aos aspectos epistemológicos, referencial teórico e método - 2000-2010

\begin{tabular}{|c|c|c|c|c|}
\hline ID & Título & Epistemologia & $\begin{array}{c}\text { Referencial } \\
\text { Teórico } \\
\text { (principal) }\end{array}$ & Método \\
\hline $\mathbf{1}$ & $\begin{array}{c}\text { A pesquisa em } \\
\text { educação no Brasil no } \\
\text { contexto do } \\
\text { pensamento } \\
\text { epistemológico de } \\
\text { Gaston Bachelard }\end{array}$ & $\begin{array}{c}\text { Os universos da epistemologia } \\
\text { bachelardiana (Bachelard } \\
\text { diurno) e da poética } \\
\text { (Bachelard noturno), } \\
\text { notadamente sua dimensão } \\
\text { "diurna" }\end{array}$ & $\begin{array}{c}\text { Sem } \\
\text { referência }\end{array}$ & \\
\hline $\mathbf{2}$ & $\begin{array}{c}\text { A questão da teoria e o } \\
\text { pragmatismo dos } \\
\text { métodos e técnicas em } \\
\text { educação }\end{array}$ & $\begin{array}{c}\text { Não explicita perspectiva, nem } \\
\text { correntes propriamente, } \\
\text { embora informe autores de } \\
\text { perspectivas epistemológicas } \\
\text { marxista e pós-crítica1 }\end{array}$ & $\begin{array}{c}\text { Lyotard, Sanches } \\
\text { Vázques e } \\
\text { Dermeval Saviani }\end{array}$ & $\begin{array}{c}\text { Sem } \\
\text { referência }\end{array}$ \\
\hline
\end{tabular}


JACOMINI, M. A.; SILVA, A. A. Pesquisas em políticas educacionais: questões epistemológicas e desafios à consolidação da área da Educação (2000-2010).

\begin{tabular}{|c|c|c|c|c|}
\hline 3 & $\begin{array}{l}\text { O papel da escola } \\
\text { superior de guerra na } \\
\text { projeção do campo } \\
\text { militar sobre o campo } \\
\text { educacional }\end{array}$ & $\begin{array}{l}\text { Explicita os conceitos de } \\
\text { referência, assumindo } \\
\text { Bourdieu como aporte teórico } \\
\text { central, notadamente os } \\
\text { conceitos de campo, habitus e } \\
\text { interesse }\end{array}$ & $\begin{array}{c}\text { Bourdieu, Cunha, } \\
\text { Azevedo, Cury, } \\
\text { Saviani e Horta }\end{array}$ & $\begin{array}{l}\text { Sem } \\
\text { referência }\end{array}$ \\
\hline 4 & \begin{tabular}{|c|} 
Educação e \\
Neopragmatismo: a \\
questão da verdade em \\
Richard Rorty e suas \\
repercussões no campo \\
da educação \\
\end{tabular} & $\begin{array}{l}\text { Epistemologia dialética crítica, } \\
\text { marxista, principalmente a } \\
\text { escola de Frankfurt }\end{array}$ & $\begin{array}{c}\text { Richard Rorty, e os } \\
\text { teóricos da escola } \\
\text { de Frankfurt }\end{array}$ & $\begin{array}{l}\text { Método } \\
\text { dialético }\end{array}$ \\
\hline 5 & $\begin{array}{c}\text { O processo da produção } \\
\text { do conhecimento em } \\
\text { educação: a questão da } \\
\text { imaginação }\end{array}$ & $\begin{array}{l}\text { O novo espírito científico de } \\
\text { Bachelard }\end{array}$ & \begin{tabular}{|c|} 
Bachelard, \\
Meksenas, Santos e \\
Gamboa, Martins, \\
Brennan, \\
Wheatlev, Bulcão e \\
Barbosa \\
\end{tabular} & $\begin{array}{c}\text { Método } \\
\text { fenomenológic } \\
\text { o de Bachelard }\end{array}$ \\
\hline 6 & \begin{tabular}{|} 
A problematização do \\
'problema': uma leitura \\
dos manuais de \\
iniciação ao ofício do \\
pesquisador em \\
educação
\end{tabular} & Epistemologia bachelardiana & \begin{tabular}{|} 
Feyerabend, Morin, \\
Lyotard e \\
Bachelard
\end{tabular} & $\begin{array}{l}\text { Fenomenologi } \\
\text { a de Bachelard }\end{array}$ \\
\hline 7 & $\begin{array}{l}\text { Pedagogia e educação: } \\
\text { a construção de um } \\
\text { campo científico }\end{array}$ & $\begin{array}{l}\text { Filosofia da ciência anglo- } \\
\text { saxônica do século XIX }\end{array}$ & $\begin{array}{l}\text { Popper, Kuhn, } \\
\text { Feyerabend }\end{array}$ & $\begin{array}{l}\text { Sem } \\
\text { referência }\end{array}$ \\
\hline 8 & \begin{tabular}{|} 
A presença da pesquisa \\
no processo de \\
implantação \\
da pós-graduação em \\
educação no Brasil \\
$(1960-1980)$ \\
\end{tabular} & $\begin{array}{l}\text { Perspectiva materialista } \\
\text { dialética }\end{array}$ & $\begin{array}{l}\text { Kosik, Limoeiro, } \\
\text { Marx, Cunha, } \\
\text { Brandão, Warde, } \\
\text { Azanha, Löwy }\end{array}$ & $\begin{array}{l}\text { Método } \\
\text { materialista } \\
\text { dialético }\end{array}$ \\
\hline 9 & $\begin{array}{c}\text { A escola pública hoje: } \\
\text { desafios e } \\
\text { possibilidades de uma } \\
\text { discussão/reflexão } \\
\text { ancorada nas } \\
\text { perspectivas teórico- } \\
\text { metodológicas de Karl } \\
\text { Marx e Paulo Freire e } \\
\text { na experiência } \\
\text { profissional de um } \\
\text { educador }\end{array}$ & $\begin{array}{l}\text { A dialética de Marx e a teoria } \\
\text { de Paulo Freire, notadamente o } \\
\text { conceito de conscientização }\end{array}$ & $\begin{array}{l}\text { Marx, Paulo Freire, } \\
\text { Kosik, Gadotti }\end{array}$ & $\begin{array}{l}\text { Método } \\
\text { filosófico }\end{array}$ \\
\hline 10 & \begin{tabular}{|} 
As publicações sobre o \\
projeto político- \\
pedagógico - 1996a \\
2006: contribuições \\
para a organização da \\
educação brasileira \\
\end{tabular} & Não explicitada informada & Vitor Paro & $\begin{array}{c}\text { Sem } \\
\text { referência }\end{array}$ \\
\hline 11 & \begin{tabular}{|c|}
$\begin{array}{c}\text { Notas Filosóficas sobre } \\
\text { desejo e prazer, política } \\
\text { e educação }\end{array}$ \\
\end{tabular} & Não informada & \begin{tabular}{|c|} 
Foucault, Deleuze, \\
Guattari, Reich, \\
Rancière, Kohan, \\
\end{tabular} & $\begin{array}{c}\text { Sem } \\
\text { referência }\end{array}$ \\
\hline
\end{tabular}


JACOMINI, M. A.; SILVA, A. A. Pesquisas em políticas educacionais: questões epistemológicas e desafios à consolidação da área da Educação (2000-2010).

\begin{tabular}{|c|c|c|c|c|}
\hline & & & Pardo & \\
\hline 12 & $\begin{array}{l}\text { A Gestão em questão: } \\
\text { da (des) construção à } \\
\text { (re) construção }\end{array}$ & Não informada & \begin{tabular}{|c|} 
Derrida, Demo, \\
Bordenave, Bobbio, \\
Nogueira
\end{tabular} & $\begin{array}{c}\text { Metodologia } \\
\text { da } \\
\text { desconstrução }\end{array}$ \\
\hline 13 & $\begin{array}{c}\text { Os estudos de educação } \\
\text { comparada } \\
\text { internacional no banco } \\
\text { de dissertações e teses } \\
\text { da capes no período de } \\
1987 \text { a } 2006 \\
\end{array}$ & Não informada & Bray \& Thomas & $\begin{array}{c}\text { Sem } \\
\text { referência }\end{array}$ \\
\hline 14 & \begin{tabular}{|} 
A construção do \\
conhecimento sobre a \\
formação do \\
administrador escolar: \\
uma análise a partir das \\
publicações nacionais
\end{tabular} & Não informada & $\begin{array}{l}\text { Anísio Teixeira, } \\
\text { Lourenço Filho, } \\
\text { Vitor Paro }\end{array}$ & $\begin{array}{c}\text { Sem } \\
\text { referência }\end{array}$ \\
\hline 15 & \begin{tabular}{|} 
A pesquisa educacional \\
sobre a escola pública \\
de ensino fundamental, \\
nos projetos e \\
relatórios de pesquisa \\
elaborados por \\
docentes das \\
universidades \\
brasileiras.
\end{tabular} & Não informada & \begin{tabular}{|c|} 
Bourdieu, Kosik, \\
Gatti, Boaventura \\
Santos, Goergen, \\
Trigueiro, \\
Aparecida Gouveia, \\
Warde, Zaia \\
Brandão, Fávero,
\end{tabular} & $\begin{array}{c}\text { Sem } \\
\text { referência }\end{array}$ \\
\hline 16 & \begin{tabular}{|} 
A relação Estado e \\
educação na produção \\
acadêmica brasileira
\end{tabular} & Não informada & \begin{tabular}{|c|} 
Conceitos de \\
espaço social, \\
campo, habitus, \\
capital e poder \\
simbólico. Autores: \\
Bourdieu, Chartier, \\
Burke, Braudel, \\
Khun \\
\end{tabular} & $\begin{array}{c}\text { Sem } \\
\text { referência }\end{array}$ \\
\hline 17 & \begin{tabular}{|c} 
O regime de progressão \\
continuada no Estado \\
de São Paulo: \\
indicadores e \\
perspectivas para \\
novas pesquisas. \\
\end{tabular} & Não informada & $\begin{array}{l}\text { Souza, Lüdke, } \\
\text { Freitas, Freitas, } \\
\text { Arroyo, Pimenta, } \\
\text { Tardif e Charlot }\end{array}$ & $\begin{array}{c}\text { Sem } \\
\text { referência }\end{array}$ \\
\hline 18 & $\begin{array}{c}\text { Planejamento escolar: } \\
\text { um estudo a partir de } \\
\text { produções acadêmicas } \\
(1961-2005)\end{array}$ & Não informada & $\begin{array}{l}\text { Braverman, Paro, } \\
\text { Freire e Drucker }\end{array}$ & $\begin{array}{c}\text { Sem } \\
\text { referência }\end{array}$ \\
\hline 19 & $\begin{array}{c}\text { As publicações da } \\
\text { ANPAE e a trajetória do } \\
\text { conhecimento em } \\
\text { educação no Brasil }\end{array}$ & Não informada & \begin{tabular}{|c|} 
Chales Peirce, \\
Wiliam James, John \\
Dewey, Richard \\
Rorty e Anísio \\
Teixeira; Lyotard, \\
Sanches Vázques e \\
Dermeval Saviani
\end{tabular} & $\begin{array}{c}\text { Sem } \\
\text { referência }\end{array}$ \\
\hline
\end{tabular}


JACOMINI, M. A.; SILVA, A. A. Pesquisas em políticas educacionais: questões epistemológicas e desafios à consolidação da área da Educação (2000-2010).

\begin{tabular}{|c|c|c|c|c|}
\hline 20 & $\left|\begin{array}{c}\text { NUPES: Protagonista de } \\
\text { uma história recente da } \\
\text { política para Educação } \\
\text { Superior Brasileira? }\end{array}\right|$ & Não informada & \begin{tabular}{|} 
Silva Jr., Oliveira e \\
Catani, Pallharini e \\
Silva Jr., Singer, \\
Sguissardi, Amaral, \\
Harvey, Fávero, \\
Chauí, Cunha, \\
Sobrinho, \\
Schugurensky \\
\end{tabular} & $\begin{array}{l}\text { Sem } \\
\text { referência }\end{array}$ \\
\hline 21 & \begin{tabular}{|c|} 
A “Educação \\
Ideológica” no Projeto \\
de Desenvolvimento \\
Nacional do ISEB \\
$(1955-1964)$
\end{tabular} & $\begin{array}{c}\text { Perspectiva materialista e } \\
\text { dialética, com base em Gramsci } \\
\text { e Goldman }\end{array}$ & \begin{tabular}{|} 
Lucien Goldman, \\
Michael Löwy, \\
Marx, Mannheim, \\
Luckács, Gramsci e \\
Bobbio. Sociologia \\
do conhecimento \\
\end{tabular} & $\begin{array}{l}\text { Materialismo } \\
\text { histórico e } \\
\text { dialético }\end{array}$ \\
\hline 22 & \begin{tabular}{|} 
A produção e circulação \\
de saberes sobre o \\
financiam entoda \\
educação no Brasil \\
(1991-2005)
\end{tabular} & Não informada & \begin{tabular}{|c|} 
Chartier, Carvalho, \\
Silva e Machado, \\
Velloso, Saviani, \\
França, Davies, \\
Santos, Earp e \\
Kornis, Paz, Claro, \\
Toledo
\end{tabular} & $\begin{array}{c}\text { Método da } \\
\text { história } \\
\text { cultural de } \\
\text { Roger Chartier }\end{array}$ \\
\hline
\end{tabular}

Fonte: elaborado pelas autoras com base na leitura das 22 teses e dissertações classificadas no eixo sete

Constatou-se, quanto aos elementos de natureza conceitual - epistemologia, referencial teórico, método e procedimentos metodológicos -, que todos os trabalhos voltados à produção do conhecimento em educação (linhas um a oito) indicaram suas perspectivas epistemológicas ou as teorias gerais assumidas como referência de análise, ou seja, apresentaram as concepções de conhecimento, de educação e de mundo que influenciaram e direcionaram a realização de suas pesquisas, ainda que, para isso, não tivessem empregado as terminologias perspectivas epistemológicas ou teorias gerais. Gaston Bachelard foi um dos autores mais influentes nesse grupo, especialmente em relação ao conceito de ciência deste filósofo. Nesses trabalhos há forte preocupação com a questão da filosofia e da ciência, o que se explicita pelas questões de pesquisa e objetivos que se propuseram. Equiparada à perspectiva bachelardiana, teve destaque também a marxista e suas vertentes, sendo referida em três das oito produções do primeiro conjunto de trabalhos. Esses trabalhos articularam o método dialético e o materialismo dialético à perspectiva epistemológica marxista e dialogaram com autores coerentes com esse viés. No caso desses trabalhos, o referencial teórico procura explicitar interfaces entre concepção de conhecimento, concepção de mundo e de educação.

Os conceitos de campo, interesse e habitus, de Bourdieu, também orientaram um dos trabalhos desse grupo, mas, como se pode notar no Quadro 2, a presença dessa 
perspectiva vai além desse trabalho, indicando a influência marcante das perspectivas críticas. Com um viés mais afeito às análises de filosofia das ciências, temos, ainda, um trabalho que tomou como epistemologia a filosofia anglo-saxônica do século XIX, Gaston Bachelard, Thomas Kuhn, Karl Popper, Paul Karl Feyerabend.

Nesse grupo de trabalhos (ainda nas linhas um a oito), observa-se coerência entre a perspectiva epistemológica e os referenciais teóricos utilizados, tanto no sentido de dialogar com aqueles que ajudaram a sustentar suas análises e conclusões, quanto em relação ao debate de conceitos, concepções e ideias. Entre os autores apresentados como referencial teórico, há desde aqueles com contribuições mais amplas acerca da ciência, como Bachelard e Khun, até os que trataram de questões mais específicas vinculadas à educação, a exemplo de Azevedo, Cunha, Cury, Santos e Gamboa.

Ainda em relação aos oito primeiros trabalhos, três fizeram referência explícita ao método, no sentido da forma como opera o pensamento para analisar e interpretar o objeto de estudo. Os métodos referenciados foram a fenomenologia, a dialética e o materialismo dialético. Em relação aos procedimentos metodológicos, todos os trabalhos indicaram as técnicas utilizadas para coleta e organização dos dados, embora nem sempre isso estivesse detalhado nos trabalhos.

No segundo bloco de trabalhos (de nove a 12), somente o primeiro indicou articulação entre a epistemologia, o referencial teórico e o método, anunciando esforço para demarcar a teoria geral que orienta a pesquisa e o posicionamento articulado à corrente libertadora de Paulo Freire (ou Pedagogia do Oprimido). Os demais não apresentaram a perspectiva epistemológica e somente o ID 12 apresentou como método a "metodologia da desconstrução". Todos eles indicaram o referencial teórico e os procedimentos metodológicos.

Os 10 trabalhos do último bloco (de 13 a 22) também se caracterizam pela ausência de indicação da perspectiva epistemológica e do método. Dos 10, apenas o ID 21 apresentou o materialismo dialético, com base em Gramsci e Goldman, como epistemologia e o materialismo histórico-dialético como método. Um trabalho (22), embora não tenha apresentado a epistemologia, apresentou como método a história cultural de Roger Chartier. Todos os trabalhos apresentaram o referencial teórico e os procedimentos metodológicos.

Nesse conjunto, observa-se que a articulação entre epistemologia, referencial teórico e método nem sempre é explicitada. A leitura completa dos textos nos permitiu 
verificar que em vários casos os autores não se preocuparam em anunciar os referenciais teórico-metodológicos presentes no trabalho. Entre os que explicitaram, houve casos em que o referencial foi apresentado em um capítulo descritivo e sem função clara para o conjunto da obra, denotando certo vício de anulação das referências conceituais para a análise do objeto de estudo. Parece haver certa dificuldade em articular as questões epistemológicas, teóricas e de método na construção da pesquisa como um todo, desde a definição sobre o que estudar, mas principalmente acerca de como usar o referencial que é anunciado para analisar/interpretar os dados e trazer novas contribuições.

Além disso, também se verificou certo apartamento entre a pesquisa empírica e o referencial teórico da pesquisa, elementos que merecem atenção e que repercutem tanto na constituição do campo como nos próprios resultados dos trabalhos. Com preocupação semelhante, Goergen (1986) alertou para os riscos do teoricismo e do empirismo nas pesquisas em educação, destacando que em nenhum dos casos há efetiva contribuição para fazer avançar o conhecimento. Observamos, no conjunto de trabalhos aqui analisados, casos em que há explicitação teórica, embora nem sempre articulada à problemática da pesquisa e outros em que, a despeito dos dados empíricos, falta referencial teórico que permita análises consistentes, tornando-se apenas interessantes descrições da realidade educacional.

Outra lacuna verificada na maioria dos trabalhos diz respeito à ausência constante de levantamentos prévios acerca de pesquisas anteriores que tenham tratado da temática que se pretende explorar. Isso tem levado a formulações de questões que não dialogam diretamente com os desafios que estão postos ao campo, como se ao pesquisador fosse facultado ignorar o que os colegas já fizeram em suas teses e dissertações, como fizeram e a que conclusões chegaram. Isso já havia sido constatado por Jacomini (2014), em trabalho que estudou a produção acadêmica sobre avaliação em regime de progressão continuada e vem sendo reiteradamente apontado como um desafio para a constituição do campo da educação.

Chamou-nos atenção também as características dos resumos. Constatamos que nem sempre eles contemplam elementos fundamentais para se constituir em um vetor de difusão da pesquisa. Elementos como objetivo, objeto de estudo, questão de pesquisa, referencial teórico, método, procedimentos metodológicos e conclusões muitas vezes são deixados de lado. 
A despeito das lacunas indicadas, há trabalhos com nítido esforço para enfrentar as questões teóricas, de método e epistemológicas da pesquisa educacional, incluído o diálogo com estudos anteriores.

\section{Algumas considerações para finalizar}

O propósito inicial da pesquisa foi investigar trabalhos de mestrado e doutorado dos programas de pós-graduação em Educação, buscando apreender possíveis movimentos de superação de lacunas epistemológicas e metodológicas que vêm sendo apontadas, em parte da literatura, como limitações para a consolidação do campo. Para isso escolhemos aqueles classificados no eixo de abordagens teóricos-metodológicas, ou seja, os trabalhos que, no universo de 1.283 teses e dissertações da área da Educação e do campo de políticas educacionais, indicaram em seus resumos que tratariam dessa temática.

Todavia os trabalhos selecionados, conforme os procedimentos informados, mesmo anunciando questões relativas à produção de conhecimento e aos aspectos teórico-metodológicos, não deram centralidade à esta temática.

Nesse contexto, a pesquisa revelou que a explicitação das perspectivas epistemológicas, articulando-as teórico e metodologicamente, não se manifestou como uma preocupação das teses e dissertações que integraram o escopo desta pesquisa. Isso sugere a permanência de problemas já indicados por pesquisadores consolidados da área, especialmente os que têm investido na problematização da produção de conhecimento, na consolidação da educação como um campo de saber e no diálogo necessário com os pesquisadores em formação.

Evidenciou-se, nesse sentido, que o crescimento exponencial da produção acadêmica não se converte automaticamente em interação e diálogo entre os pesquisadores mais experientes e aqueles que estão em formação. Pelo contrário, há hiatos nos ciclos de produção, os quais ainda são marcados por ambivalências na relação entre a produção, difusão e os interesses científicos em jogo. Isso, ao nosso ver, indica demanda por estudos que avancem quanto à existência dessas ambivalências, tendo em vista a superação das críticas de ordem teórico-metodológica em pauta desde a década de 1970 e a consolidação da área da Educação e o campo das políticas educacionais.

Entrementes, a experiência dessa pesquisa, sugere, assim como defendido por André (2001), que a tarefa de estudar a produção acadêmica em Educação, na fronteira 
mais direta das políticas educacionais, deve ser enfrentada de forma sistêmica e não apenas por grupos ou instituições isoladas. Nesse movimento, a presença de pesquisadores mais experientes e o diálogo com a produção existente apresentam-se como condições essenciais.

Como espaço de luta que produz formas particulares de ilusio em torno dos interesses científicos em jogo, não podemos perder de vista, contudo, a complexidade do desafio posto, desde a condição de área que opera com conceitos produzidos em interseção com outros campos, até os enfrentamentos políticos ao credencialismo que se impõe entre nós e que, na atualidade, além de cindir possibilidades de equidade entre os campos de conhecimento, também forja práticas de fraude que anulam o sentido social do trabalho acadêmico. No dizer de Maranhão, Santos e Ferreira (2017, p. 251) “o trabalho acadêmico torna-se um fetiche: algo para se ter, sem alma, vazio por si só, cuja existência se justifica nele mesmo, como ícone de uma atividade potencialmente emancipatória, mas que perdeu todo o seu sentido crítico". A constituição do campo, pois, não se apresenta como uma tarefa simples aos que não se desconectaram da relação entre o lugar social da investigação e os seus desafios históricos. 0 tema continua em pauta.

\section{Referências}

ANDRÉ, M. Pesquisa em educação: buscando rigor e qualidade. Cadernos de Pesquisa, São Paulo, n. 113, p. 51-64, jul. 2001.

AZANHA, J. M. P. Uma ideia de pesquisa educacional. São Paulo: Edusp, 1992.

BOURDIEU, P. Os usos sociais da ciência: por uma sociologia clínica do campo científico. São Paulo: Edunesp, 2004.

CUNHA, L. A. Os (des) caminhos da pesquisa na pós-graduação em Educação. In: Seminário sobre a produção científica nos programas de pós-graduação em educação, 1979, Brasília, DF. Anais... Brasília, DF: MEC/Capes, 1979. p. 3-15.

DAMASCENO, M. N. Questões teóricas e práticas da pesquisa social e educacional. Em Aberto, Brasília, ano 5, no 31, p. 31-4, jul./set. 1986.

GAMBOA, S. S. Pesquisa em educação: métodos e epistemologias. 2. ed. Chapecó: Argos, 2012.

Epistemologia da pesquisa em educação: estruturas lógicas e tendências metodológicas. Tese (Doutorado). Faculdade de Educação. Universidade Estadual de Campinas. Campinas, 1987, 240 p.

GATTI, B. A. A construção da pesquisa em educação no Brasil. Brasília, DF: Liber Livro, 2012. 
GOERGEN, P. A pesquisa educacional no Brasil: dificuldades, avanços e perspectivas. Em Aberto, Brasília, ano 5, no 31, p. 1-18, jul./set. 1986.

GOUVEIA, A. J. A pesquisa educacional no Brasil. Revista Brasileira de Estudos Pedagógicos, v. 55, n. 122, abr. - jun., 1971, p. 209 - 241.

JACOMINI, M. A. Avaliação da aprendizagem em tempos de progressão continuada: o que mudou? Um estudo de teses e dissertações sobre o tema (2000-2010). Ensaio: Avaliação e Políticas Públicas em Educação, Rio de Janeiro, v. 22, n. 84, p. 807-828, jul./set., 2014.

KUENZER, A. Z. A pesquisa em educação no Brasil: algumas considerações. Em Aberto, Brasília, ano 5, no 31, p. 19- 19-24, jul./set. 1986.

KUHN, T. S. A estrutura das revoluções científicas. 9. ed. São Paulo: Perspectivas, 2005.

LOSADA LORA, Rodrigo; CASAS CASAS, Andrés. Enfoques para el análisis político: história, epistemologia y perspectivas de la ciencia política. 1. ed. Bogotá: Editorial Pontificia Universidad Javeriana, 2010.

MACEDO, E.; SOUSA, C. P. A pesquisa em educação no Brasil. Revista Brasileira de Educação, Rio de Janeiro, n. 43, p. 166-176, jan./abr. 2010.

MAINARDES, J.; TELLO, C. A pesquisa no campo da política educacional: Explorando diferentes níveis de abordagem e abstração. Arquivos Analíticos de Políticas Educativas, Arizona State University, v. 24, n. 75, 2016.

MARANHÃO, C. M. S. de A.; SANTOS, F. C. P. dos; FERREIRA, P. T. M. Banalização da fraude acadêmica: reflexões à luz da teoria da semicultura de Adorno. Educação \& Sociedade, São Paulo: Cortez; Campinas: CEDES, v. 38, n. 138, p. 249-263, jan./mar. 2017.

MASSOM, G. Materialismo histórico e dialético: uma discussão sobre as categorias centrais. Revista Práxis Educativa, Ponta Grossa, v. 2, n. 2, p. 105-114, jul./dez. 2007.

NOSELLA, P. A pesquisa em educação: um balanço da produção dos programas de pósgraduação. Revista Brasileira de Educação, Rio de Janeiro, n. 43, p. 177-183, jan./abr. 2010.

TELLO, C. Las epistemologias de la política educativa: notas históricas y epistemológicas sobre el campo. In: TELLO, César (coord. y compilador). Epistemologías de la política educativa: posicionamientos, perspectiva y enfoques. Campinas: Mercado das Letras, 2013, p. 23-68.

TELLO, C.; MAINARDES, J. La posición epistemológica de los investigadores em política educativa: debates teóricos em torno a las perspectivas neo-marxista, pluralista y posestruturalista. Archivos Analíticos de Políticas Educativas, [s. l.], v. 20, n. 9, p. 1-33, mar. 2012.

WARDE, M. O papel da pesquisa na pós-graduação em Educação. Cadernos de Pesquisa, São Paulo, v. 73, p. 67-75, maio 1990. 

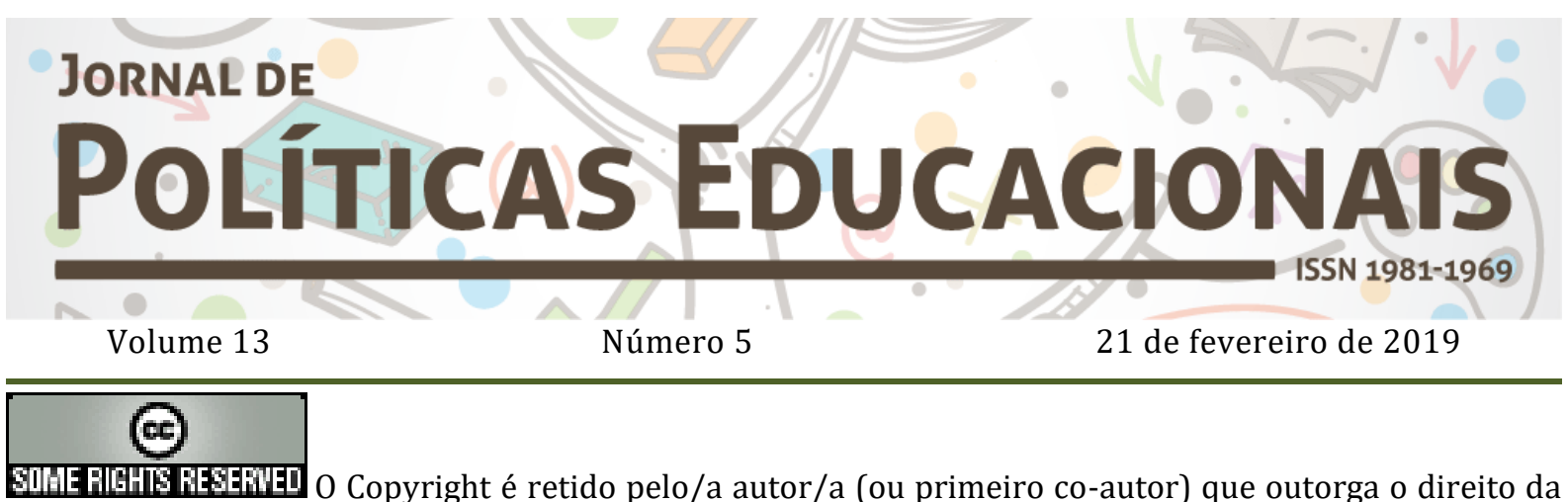

0 Copyright é retido pelo/a autor/a (ou primeiro co-autor) que outorga o direito da primeira publicação ao Jornal de Políticas Educacionais. Mais informação da licença de CreativeCommons encontram-se em http://creativecommons.org/licenses/by-nc-nd/2.5. Qualquer outro uso deve ser aprovado em conjunto pelo/s autor/es e pelo periódico.

JoRnal DE Políticas Educacionais é uma publicação do Núcleo de PolíticasEducacionaisdo Setor de Educação da Universidade Federal do Paraná - NuPE/UFPR, em consórcio com a Linha de Pesquisa em Políticas Educacionais do Programa de Pós-Graduação em Educação - PPGE/UFPR, que aceita colaboração, reservando-se o direito de publicar ou não o material espontaneamente enviado à redação. As colaborações devem ser enviadas ao NuPE/UFPR, conforme orientações contidas nas páginas do periódico na internet: http://revistas.ufpr.br/ipe.

\author{
Indexação: \\ BBE - Biblioteca Brasileira de Educação (MEC/INEP) \\ Clase (Base de Datos Bibliográfica de Revistas de Ciencias Sociales y Humanidades) \\ Diadorim - Diretório de Política de Acesso Aberto das Revistas Científicas Brasileiras (IBICT) \\ Google Scholar \\ Index Copernicus \\ Portal de Periódicos (Capes) \\ SER - Sistema Eletrônico de Revistas da Universidade Federal do Paraná (SER/UFPR) \\ Sumários de Revistas Brasileiras (FUNPEC-RP) \\ DRJI - Directory of Research Journals Indexing
}

(Periódico integralmente disponível apenas em via eletrônica)

Jornal de Políticas Educacionais / Núcleo de Políticas Educacionais da Universidade Federal do Paraná NuPE/UFPR - v.1, n. 1 (1ํㅗ을 semestre de 2007) - Curitiba: NuPE/UFPR.

Volume 13, número 5 - Fevereiro de 2019

ISSN 1981-1969

1. Educação - Periódicos. 2. Política Educacional - Periódicos. I. NuPE/UFPR

Comitê Editorial:

Elisângela Scaff (UFPR)

Ana Lorena Bruel (UFPR)

Gabriela Schneider (UFPR)

Conselho Editorial:

Andréa Barbosa Gouveia (UFPR), Ângela Hidalgo (UNICENTRO), Cesar GernominoTello (Universidad Nacional TresFebrero, Argentina),Gladys Beatriz Barreyro (USP), Juca Gil (UFRGS), Jefferson Mainardes 
(UEPG), João Ferreira de Oliveira (UFG), Luiz Souza Júnior (UFPB), Marcos Edgard Bassi (UFSC), Regina Maria Michelotto (UFPR), Robert Verhine (UFBA), Rosana Cruz (UFPI), Rubens Barbosa Camargo (USP), Sebastián Donoso Díaz (Universidad de Talca, Chile), Taís Moura Tavares (UFPR), TheresaAdrião (UNICAMP), Vera Peroni (UFRGS).

Créditos e Agradecimentos:

Revisão de Língua Portuguesa, Abstract e Resumen: PROGRAMA DE APOIO ÀS PUBLICAÇÕES CIENTÍFICAS PERIÓDICAS DA UFPR

Arte e diagramação: TIAGO TAVARES (tiagotav@gmail.com)

Jornal de Políticas Educacionais

Universidade Federal do Paraná

Setor de Educação

Núcleo de Políticas Educacionais - NuPE/UFPR

Avenida Sete de Setembro, 2645

$2^{\circ}$ andar, Sala 213

80.230-010 - Curitiba - PR - Brasil

Tel.: 41-3535-6264

jpe@ufpr.br

http://revistas.ufpr.br/jpe 